
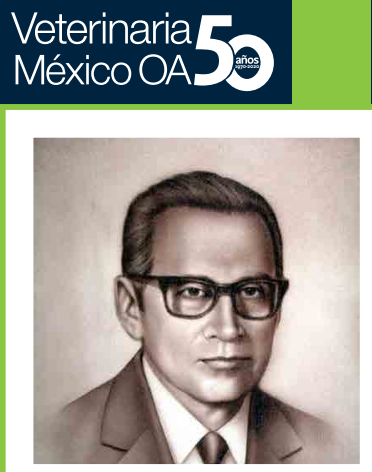

Manuel Chavarría Chavarría

El Dr. Manuel Chavarría Chavarría fue Biólogo

y Médico Veterinario por la Universidad Nacional Autónoma de México. En 1933 descubrió una nueva especie de infusorio del intestino del caballo nombrándolo Ochoterenaia appendiculata. Destacan sus estudios taxonómicos de parásitos de cerdo, equinos, bovinos, gallinas y palomas. Dos lineas de investigación tuvieron particular trascendencia. La primera concierne la garrapata del ganado y la piroplasmosis, sentando las bases para establecer la campaña nacional contra la garrapata del ganado. La segunda línea derivó en su contribución más importante que fue el desarrollo de un tratamiento para la cisticercosis cerebral humana. La UNAM le otorgó el emeritazgo en 1979.

* Profesor Emérito de la Universidad Nacional Autónoma de México

${ }^{1}$ Fundador de la Unidad de Neurología y Neurocirugía del Hospital General de México. Actual Consultor de dicha Unidad, México, DF

2 Profesor de Parasitología de la Facultad de Medicina Veterinaria y Zootecnia, UNAM, México, DF

Artículo original publicado en: Salud Pública de México 1979;21:603-18.

a Trabajo presentado en la sesión de la Academia Nacional de Medicina como homenaje al Dr. Clemente Robles.

NOTA DEL DR. CLEMENTE ROBLES: La Idea original de tratar la cisticercosis cerebral humana con Prazlquantel me fue sugerida por el Dr. Manuel Chavarría Chavarría, que por su condición de médico veterinario no podía continuar sus estudios en el hombre; la realización en la práctica la hemos hecho juntos.

Robles C, Chavarría Chavarría M. Presentación de un caso clínico de cisticercosis cerebral tratado médicamente con un nuevo fármaco: Praziquantel. Salud Pública de México. 1979;XXI:603-18.

Publicado: 2020-09-30

Información y declaraciones adicionales

en la página 15

() Derechos de autor:

Clemente Robles et al. 2020

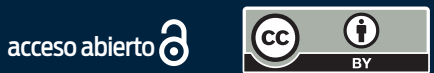

Distribuido bajo una Licencia Creative Commons Atribución 4.0 Internacional (CC-BY 4.0)0
Veterinaria

Vol. 7 | No. 3 | Julio-Septiembre | 2020

SALUD PÚBLICA DE MÉXICO

ÉPOCA V. VOLÚMEN XXI. NÚMERO 5

SEPTIEMBRE-OCTUBRE DE 1979

\title{
Presentación de un caso clínico de cisticercosis cerebral tratado médicamente con un nuevo fármaco: Praziquantel $^{\mathrm{a}}$
}

Clemente Robles ${ }^{1}$

Manuel Chavarría Chavarría*2

\section{Resumen}

La cisticercosis es problema grave en los países latinoamericanos y otros, no ha habido tratamiento médico; la cirugía es satisfactoria en pequeño porcentaje de los enfermos. La experimentación sobre el tratamiento de la cisticercosis en el cerdo, realizada por Chavarría con praziquantel demostró que se puede exterminar a los cisticercos alojados en el tejido muscular y en los centros nerviosos. Logrado este objetivo, se planteó con el Dr. Robles la traspolación de estos resultados al hombre y se aplicó el tratamiento a un niño de 6 años. Primero se cumplieron los requisitos para experimentar en humanos que indica la Carta de Helsinki y se levantó acta con los padres del paciente, sabedores de que se usaría nuevo medicamento veterinario de acción y reacciones desconocidas en humanos. Se aprovechó este caso ya estudiado y con diagnóstico elaborado y verificado en varias instituciones; este caso es de cisticercosis intracerebral múltiple, diseminada, con lesiones supra e infratentoriales, con pronóstico fatal, que está ampliamente probado por la observación clínica.

El enfermo fue hospitalizado en un centro de reconocida solvencia y con amplios recursos humanos de laboratorio, equipo, etc., para hacer frente a cualquier emergencia. La droga fue administrada por vía oral a la dosis de $50 \mathrm{mg} / \mathrm{kg}$ de peso en 24 horas durante 15 días. Para prevenir complicaciones el primer autor (Robles) creyó conveniente administrar prednisona a la dosis diaria y oral de $30 \mathrm{mg}$ durante la realizaclón del estudio con muy buenos resultados; también se administró fenobarbital a la dosis de 0.05 diariamente. El enfermo era examinado clínicamente todos los días: signos

Cite this as:

Robles C, Chavarría Chavarría M. Presentación de un caso clínico de cisticercosis cerebral tratado médicamente con un nuevo fármaco: Praziquantel. Veterinaria México OA.

2020:7(3). doi:10.22201/fmvz.24486760e.2020.3.924. 
vitales cada 6 horas; frecuentes determinaciones de biometría hemática, orina, química sanguínea, dosificación de protrombina, determinación del tiempo de coagulación y de sangrado; pruebas de funcionamiento hepático, dosificaciones de bilirrubinas, transamínasas y deshidrogenasa láctica. No hubo ningún fenómeno de intolerancia, tampoco las reacciones alérgicas que han sido señaladas. Con el pronóstico fatal de esta forma clínica de cisticercosis que diversos médicos anunciaron a la familia y en lo cual coincidíamos, el caso nos pareció ideal para usar por primera vez en el ser humano un medicamento ya probado en voluntarios humanos con resultados de inocuidad y perfecta tolerancia. Había sido tratado diariamente con 16 mg de Dexametasona y 7 mg de Fenobarbital. El enfermo presentaba desde hacía dos meses violento cuadro de hipertensión craneana, cefalea, vómitos, crisis oculogiras a la derecha y crisis convulsivas, diplopía y edema pupilar. Reacción de complemento (Nieto) positiva a 1.o ml. Díagnóstíco de neurocisticercosis intracerebral difusa, generalizada y bilateral y además teniasis. Electroencefalograma: desorganización y lentificación de base difusa en ambos hemisferios cerebrales. TAC: múltiples procesos granulomatosos tanto supra como infratentoriales con edema periférico.

Después del tratamiento, el niño está completamente asintomático y sin tratamiento desde hace tres meses. Los exámenes de laboratorio de control mencionados, normales. LCR Pandy, bacterioscopia y cultivos negativos. Reacción de fijación de complemento negativo. Electroencefalograma normal. Reacciones inmunológicas sugieren que el parásito está muerto: la reacción antigénica ha desaparecido. Radiología: desaparecen completamente las formas anulares características de la presencia del cisticerco y el edema correspondiente.

Se puede concluir que el praziquantel es eficaz en el tratamiento de la cisticercosis cerebral, extermina a los cisticercos y la enfermedad se cura. En el presente caso no hubo reacciones alérgicas ni fenómenos tóxicos ni de intolerancia.

\section{Abstract \\ Presentatlon of a clinical case of cerebral cystlcercosis treated medically with a new drug}

Cysticercosis 15 a great danger in latinoamerican countries and some others, no medical treatment is known surgery is satisfied in small percentage of cases; the experiments made in swine treatment demonstrated that it is possible to exterminate the parasites lodged in muscular tissue as in the nervous centers; this was the initial phase of the investigations performed by one of the authors (Chavarría). Once this objective was achieved, it was planned with Dr. Robles to transfer results on man, and treatment was applied to a six years old boy. At first requirements were accomplished for experimenting on humans which Helsinki Chart Indicates, one act was sta- 
blished with the patient's parents, who were well aware that of veterinary medication or treatment would be used whose action and reactions are unknown on humans. This case was studied and used with advantage, diagnosis was made and verified by various institutions, it was parenchymatous, multiple, intracerebral cysticercosis with supra and infratentorial lesions, with fatal prognosis, which fully proven by clinical observations. The patient was hospitalized in a trust worthy medical center and with complete laboratory resources, good medical staff, equipment etc. in order to meet any emergency. Medication was given at a dose of $50 \mathrm{mg} /$ patient's weight every 24 hours during two weeks. In order to prevent complications the senior author considered the use of Prednisone convenient at adose of 30 mg per day orally during the duration of the research period. Fenobarbital was also administered at the dose $0.05 \mathrm{~g}$ daily with very good promising results. The patient was examined clinically every day, vital signs taken every six hours, frequent determinations hematic biometry, urine, blood chemistry, protrombine dosifications, determinations on blood coagulation and bleeding time, liver functioning, dosification on bilirubins, transaminases and lactic dehydrogenase. No reaction of intolerance of allergic reaction has been observed. With fatal prognosis of this clinical form of cysticercosis, which various physicians made known to the patient's family and on which we agreed upon the case was ideal in our opinion to be used for the first time on a human being, one medication already tested on voluntary people with results of inocuity and complete tolerance. The patient had been treated daily with $16 \mathrm{mg}$ of Dexametasona and $7 \mathrm{mg}$ of Fenobarbltal. $\mathrm{He}$ presented two months before violent picture of cranial hypertensioncephalea, vomit, oculogyration to right, convulsive crisis, diplopia and papillary oedema. CFT (Nieto) positive to $1.0 \mathrm{ml}$. Diagnosis of billateral, generalized, diffused, and intracerebral cysticercosis and moreover taenlasis. Electroencephalogram: disorganization and identification of diffuse base in both cerebral hemispheres. CAT: multiple granulomatose processes supra and infratentorials with peripheral cedema.

After this treatment the patient is completely asymptomatic and has received no further medical treatment during the past three months. The laboratory tests on the above mentioned control are normal. CRL Pandy, bacterioscopy and cultures negatives. CFT negative. Normal electroencephalogram. Immunological reactions suggest that the parasites are exterminated, the antigenic reactions have disappeared. X rays: disappear completely the annular shadows.

Conclusions may be trusted that the praziquantel is efficient for the treatment of cerebral cysticercosis, it exterminates the cysticerci and cures the disease. in the present case, there were neither allergyc reaction or intolerance or toxic phenomena. 


\section{Introducción}

La cisticercosis es una enfermedad común al hombre y al cerdo causada por la infestación con la larva (forma intermedia o cisticerco) de Taenia solium (Cysticercus cellulosae).

Las larvas pueden alojarse en cualquier tejido u órgano, pero lo hacen de referencia en el tejido celular subcutáneo, en los músculos, las vísceras y el sistema nervioso central; el lugar de elección es el cerebro; las vesículas son redondeadas u ovales de cerca de $5 \mathrm{~mm}$ de diámetro; están formadas por una membrana anhista que contiene en su interior un líquido claro como agua de roca y a la larva o escólex como un grano de arroz (Figura 1).

Por su frecuencia y gravedad, esta enfermedad constituye serio problema de salud pública y de enorme daño económico por la destrucción de la carne de cerdos contaminados a que obliga. He aquí algunos datos:

En 1935 Ochoterena ${ }^{1}$ estudió histopatológicamente algunos cerebros provenientes del Manicomio General enviados por Salazar Viniegra: se trataba de cisticercosis cerebral. En 1939 Rojo de la Vega ${ }^{2}$ operó a un enfermo de Ramírez Moreno que presentaba un quiste cerebral cisticercoso.

Ugalde $^{3}$ y Guevara Oropeza ${ }^{4}$ reportaron sendos casos, uno de necropsia y otro operatorio intervenido por Mariano Vázquez.

Hasta aquí se trata de sorpresas operatorias o anatomopatológicas, pero la verdadera frecuencia de la enfermedad era desconocida.

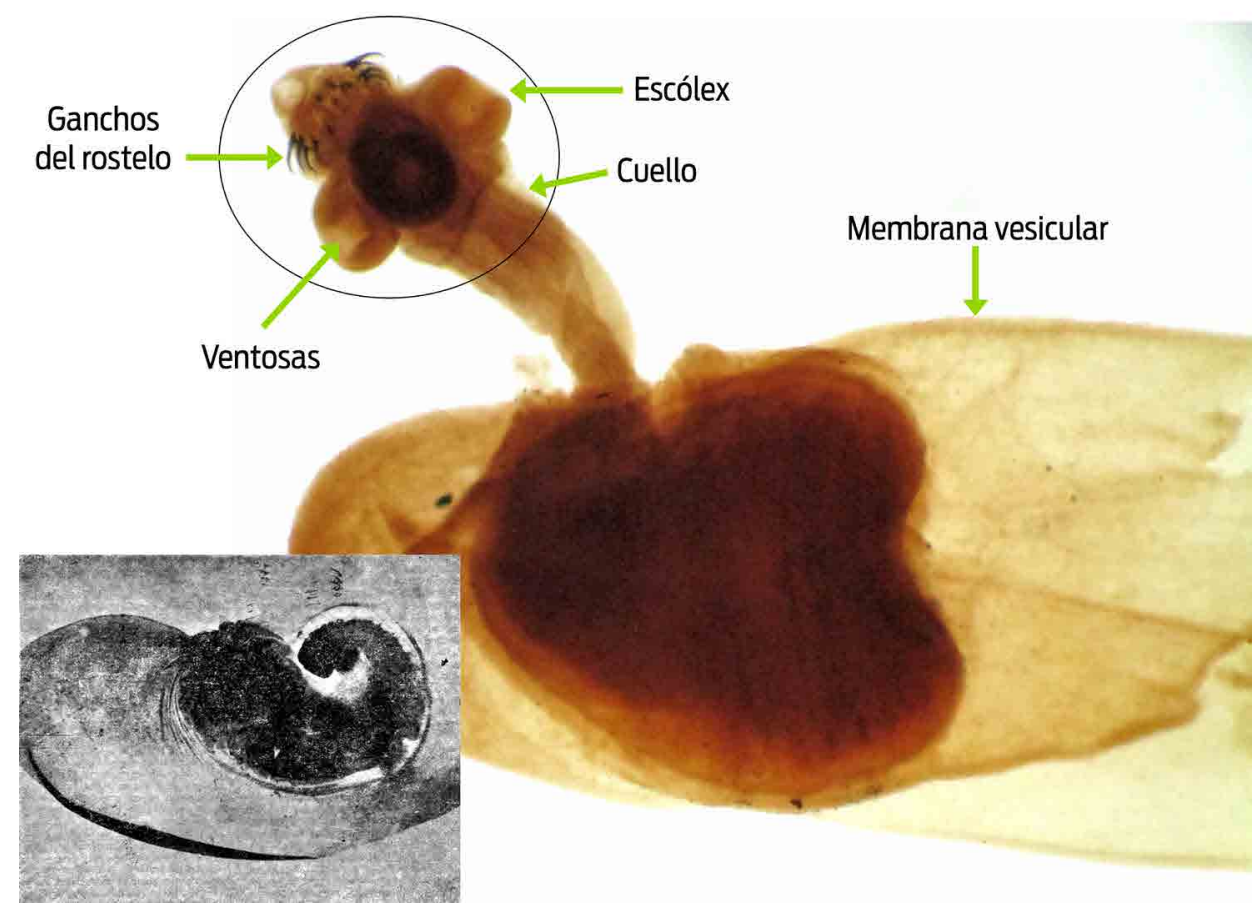

Figura 1. Cisticerco completo; muestra el escólex, el cuello y la membrana vesicular con su invaginación. Creditos a Dr. Juan Antonio Figueroa Castillo, Departamento de Parasitología, UNAM. 
En 1937 Robles fundó el Servicio de Neurocirugía del Hospital General en el Pabellón 7 y comenzó a registrar en forma sistematizada la frecuencia de esta parasitosis y su enorme interés para la patología nacional.

En $1941^{5}$ llamó la atención de la Academia Nacional de Medicina instándola a dirigirse a las autoridades sanitarias a efecto de tomar las medidas que se juzgaran oportunas, tal y como en efecto lo hizo la Academia; simultáneamente, otras personas se ocuparon en nuestro medio del problema, mereciendo citarse en primer término a Costero, ${ }^{6}$ cuya ayuda ha sido valiosísima, pues con el material del Hospital General hizo la clasificación de las lesiones.

Con motivo de la celebración de la VI Asamblea Nacional de Cirujanos, la sección de Neurocirugía señaló como tema de ponencia la cisticercosis cerebral, habiéndose presentado contribuciones importantes por Mazzoti, Gamboa, León y Robles.

Mazzoti en $1944^{7}$ reportó que en 4000 análisis coproparasitoscópicos, 2\% resultó positivo a Taenia solium. Robles en $1946^{8}$ publicó un resumen de la clasificación anatomoclínica elaborada con la colaboración de Costero, para entonces ya tenía 47 casos perfectamente estudiados; esta clasificación anatomoclínica permanece clásica.

Briseño, ${ }^{9}$ Biagi y Martínez reportaron de 97 autopsias realizadas, 3.5\% positivas al cisticerco cellulosae. Cifras semejantes a la de Costero, ${ }^{10}$ quien encontró el cisticerco en 3.6\% de todas las autopsias realizadas en el Hospital General.

En 1940 Robles $^{11}$ entre 182 operaciones realizadas por presunto tumor cerebral, encontró la cisticercosis en $25 \%$ de los casos.

Informa también la Dirección General de Control de Alimentos, Bebidas y Medicamentos que en los años 1968 y 1969, al llevar el control de ocho rastros ubicados en la periferia del D. F., en los que sacrificaron 898,463 cerdos, resultaron motivo de decomiso principalmente por cisticercosis 11,159.

Recientemente son numerosos los autores que se han ocupado del tema, de ellos pueden citarse los siguientes: Nieto, D., Escobar, A., González, D., Márquez, M. H., Austria, B., Pérez Tamayo, R., Flores Barroeta, F., Rabiela, M. T., Lombardo Rivera, L., Ridaura, S. C., López Corrella, F., etc.

En lo referente al diagnóstico de laboratorio, se han estudiado las modificaciones del LCR y entre otras las siguientes: pleocitosis, hiperalbuminorraquia, hiperglobulinorraquia, hipoglucorraquia, disminución de cloruros y muy especialmente el aumento de eosinófilos. El diagnóstico biológico ha sido el tema de otro grupo de investigadores, de los cuales cabe citar especialmente a Nieto, Williams y Gutiérrez M.

Con el auxilio de los rayos $\mathrm{X}$ se han logrado impresionantes adelantos, desde luego se han precisado las características de las calcificaciones cisticercosas; con medios de contraste: aire y radioopacos, se ha afinado el diagnóstico, pero con la tomografía axial computarizada, sola o con inyección de medios de contraste, es posible establecer el diagnóstico con absoluta precisión y hasta en sus más finos detalles, como sitio y número de las vesículas. 
Contrastando con lo mucho que se ha logrado en el terreno de la clínica, la patología, el diagnóstico biológico, el radiológleo y el de laboratorio, es poco lo que se ha avanzado en la terapéutica. Esto se debe a las siguientes razones:

Las lesiones generalmente son múltiples, generalizadas y bilaterales; los medicamentos que matan la tenía lo hacen en el intestino, se absorben difícilmente y no pasan la barrera hematoencefálica.

En lo tocante a la cirugía, ofrece poco, lo más a menudo paliación de los síntomas con operaciones descomprensivas o derivativas, como lo precisó Robles en 1966, ${ }^{12}$ reportando a la Academia las ventajas del uso de la sonda de Puddenz.

La cirugía pocas veces cura radicalmente; lógico es que, cuando aparecieron fármacos que se absorben con facilidad en el intestino y que son capaces de atravesar la barrera hematoencefálica, se viera un rayo de esperanza para encontrar un tratamiento verdaderamente radical.

Salazar Mallén en $1972^{13}$ hizo ensayos con el hetrazan y el metrifonato, llegando a demostrar que estos medicamentos son capaces de matar al cisticerco y de llegar a mejorar a ciertos enfermos, pero desgraciadamente tiene elevado poder tóxico y su uso no se ha generalizado.

De lo anterior, se deduce que el tratamiento de la cisticercosis es un problema no resuelto, que pocos enfermos curan y que generalmente los que mejoran quedan con graves incapacidades o secuelas neurológicas definitivas.

A. praziquantel. El preparado es un derivado de un sistema heterocíclico nuevo del pirazino isoquinolina. El nombre universal es praziquantel y se vende con dos nombres comerciales: Embay 8440 y Droncit, resultante de investigaciones llevadas a cabo juntamente por Bayer A. G. Leverkusen y E. Merck, cuya actividad antiparasitaria fue demostrada por este último en el hombre.

La droga pura se presenta en forma cristalina, prácticamente sin olor ni color, de gusto amargo. Estable en condiciones normales, se funde a $136-140{ }^{\circ} \mathrm{C}$. Es soluble en cloroformo y en dimetisulfóxido, ligeramente soluble en alcohol y muy poco en agua.

Droncit se absorbe rápidamente en el intestino y se elimina pronto de la circulación sanguínea; a las dos horas quedan indicios en el digestivo. Se supone que se metaboliza total y rápidamente. No hay barrera hematoencefálica, Andrews, 1976. ${ }^{14}$ El hígado lo inactiva.

El Droncit marcado $\mathrm{C}^{14}$ se localiza fundamentalmente en el hígado y riñones. La droga pura y sus metabolitos se eliminan tan aprisa que a las 24 horas casi no queda nada.

Inyectado por vía endovenosa se elimina por la mucosa gastrointestinal, según Steiner, $1976 .^{15}$

Por vía endovenosa, la droga y sus metabolitos se absorben rápidamente por los tejidos; se elimina de los vasos en tres a ocho horas; la droga pura, en una hora; por vía oral la concentración máxima se logra en 30 minutos a una hora. La excreción total de Droncit y metabolitos se efectúa en 24 horas; los riñones son la vía fundamental de acuerdo con Steiner, $1976 .{ }^{15}$

La tolerancia es muy grande, Mürmann, $1976,{ }^{16}$ la $\mathrm{DL}^{50}$ en ratas y ratones es de 2000 a 3000 mg/kg de peso y aún mayor por vía subcutánea (la menor dosis 
suficientemente activa contra una solitaria es $1 \mathrm{mg}$ por $\mathrm{kg}$ y la máxima necesaria es $5 \mathrm{mg}$ contra la tenia equinococo que es, según parece, la más resistente). En perros hay efecto emético con $200 \mathrm{mg}$ por kg; sin embargo, toleran $180 \mathrm{mg}$ por kg como dosis diarias durante un mes, sin daño aparente. No hay irritación en mucosas (prueba en mucosa ocular de consejos) ni en la piel (pruebas en cuyos y en humanos). En ratas y en conejos gestantes no se observan efectos embriotóxicos ni teratogénicos en dosis hasta de 180 mg por kg durante los días sexto a decimoquinto y sexto a decimoctavo postcoitum, respectivamente.

Su acción cestocida en el caso de los adultos, de manera general, es 100\% letal aunque con dosis variable de una especie a otra. Estudios experimentales en diversas especies animales han demostrado alta efectividad contra toda especie de Schistosoma patógena al hombre. También se ha demostrado eficacia curativa contra gran variedad de céstodos.

Intensos estudios de toxicologia y farmacología han demostrado buena tolerancia en los animales de experimentación. Estudios muy cuidadosos en voluntarios humanos con dosis supuestas terapéuticas no han revelado signos ni de toxicidad ni de intolerancia, ${ }^{17}$ según Leopold et al.

B. Manuel Chavarría, M.V.Z. ${ }^{18}$ ha estudiado, desde el punto de vista, primero experimental en el cerdo y otros animales de laboratorio, las propiedades antihelmínticas de este nuevo preparado, confirmando que goza de alta eficacia.

Posteriormente lo usó en el tratamiento de la cisticercosis en el cerdo, haciendo numerosas experiencias con diversas dosificaciones y demostró que a la dosis de $50 \mathrm{mg}$ por $\mathrm{kg}$ de peso, administrado por vía oral, causa la muerte de los cisticercos y la curación de la enfermedad al cabo de 15 días de administración.

C. En el Instituto de Enfermedades Tropicales de esta ciudad, Molina Pasquel ${ }^{19}$ ha utilizado el preparado en dos casos de cisticercosis subcutánea, obteniendo en un caso resultados que podrían llamarse alentadores, usando dosis hasta de $25 \mathrm{mg}$ por $\mathrm{kg}$ de peso por tres días.

Si el nuevo preparado praziquantel es eficaz en el tratamiento de la cisticercosis del cerdo, incluso la cerebral, si ya ha sido probado en voluntarios humanos y se ha demostrado que no es tóxico ni produce reacciones indeseables, si ya ha sido usado en el hombre en el tratamiento de la teniasis y de la cisticercosis subcutánea con buenos resultados; y si por otra parte la cisticercosis cerebral del hombre sigue siendo una enfermedad sin tratamiento quimioterapéutico eficaz, deberá ensayarse en un número de casos con el fin de aclarar cuál es su valor terapéutico.

Esta es la hipótesis de trabajo que hay que tratar de demostrar y sería la finalidad del estudio que proponernos.

1 Material: el material de este estudio se contrae a un solo caso de cisticercosis intracerebral múltiple, diseminada con lesiones supra e infratentoriales en un niño de 6 años de edad.

- Método: el método fue el de experimentación abierta sin testigos, pues la evolución fatal de esta forma de cisticercosis es bien conocida. 
1 Diseño experimental: el estudio se diseñó escogiendo un caso cuyo pronóstico fatal está ampliamente probado por la observación clínica.

El enfermo, y con amplios recursos humanos, de laboratorio, equipo, etc., para poder hacer frente a cualquier emergencia.ara su mejor control, fue hospitalizado en un centro de reconocida solvencia.

El medicamento fue administrado por vía oral a la dosis de $50 \mathrm{mg}$ por $\mathrm{kg}$ de peso en 24 horas, administrado durante 15 días, repartiendo la dosis diaria en tres tomas, una con cada comida, se usaron cápsulas que contenían el medicamento en polvo.

Para prevenir complicaciones se administró prednisona a la dosis de $30 \mathrm{mg}$ diariamente por vía oral durante toda la duración del estudio; también se administró fenobarbital a la dosis de $0.05 \mathrm{~g}$ diariamente.

Durante el lapso de hospitalización el enfermo fue examinado clínicamente todos los dias, tomando sus signos vítales cada seis horas; se hicieron frecuentes determinaciones de biometría hemática, orina, química sanguínea, dosificación de protrombina y determinación del tiempo de coagulación y de sangrado. Se hicieron también pruebas de funcionamiento hepático, dosificaciones de bilirrubinas, transaminasas y deshidrogenasa láctica.

No hubo ningún fenómeno tóxico o de intolerancia; a los ocho días aparecieron huellas de albúmina en la orina que desaparecieron espontáneamente en 48 horas. Tampoco se registraron las reacciones alérgicas que han sido señaladas en atención al pronóstico fatal de esta forma clínica de cisticercosis que diversos médicos enunciaron a la familia y en lo cual coincidíamos; el caso nos parecía ideal para usar por primera vez en el ser humano un medicamento que previamente había sido administrado a voluntarios, quedando claramente demostrado que es inocuo y perfectamente tolerado, con lo cual se satisfacía el requisito que señala la Carta de Helsinky para experimentación en el hombre.

$\mathrm{Al}$ otorgarme la familia un permiso legal bastante amplio, quedó también satisfecho este requisito.

Para ponernos a cubierto de sorpresas desagradables al pasar el uso del medicamento de los animales de experimentación al hombre, seguimos los sabios consejos del doctor Rafael Méndez y principiamos administrando una dosis equivalente a la décima parte de la dosis supuesta terapéuticamente durante tres días, luego la subimos a $50 \%$ otros tres días y al término de este plazo usamos la dosis completa.

\section{Presentación del caso clínico}

O. D. L., seis años, masculino, escolar. Antecedentes sin importancia. Se inicia hace dos meses con violento cuadro de hipertensión intracraneana, cefalea constante, vómitos, crisis oculogiras a la derecha y crisis convulsivas de inicio local en miembro superior izquierdo que después se generalizan. Hay diplopía y severas alteraciones del fondo del ojo (edema papilar). No hay fenómenos de localización. 


\section{Exámenes de laboratorio}

Examen coproparasitoscópico positivo a huevecillos y proglótide de tenia.

Líquido cefalorraquídeo: presión inicial, 180, presión final, 140; proteínas, 12.5; glucosa, 60 mg; células, 2.

Reacciones de hemaglutinación e inmunológicas negativas a la cisticercosis.

Reacción de Nieto, positiva a $1.0 \mathrm{ml}$.

Diagnóstico: neurocisticercosis intracerebral, difusa, generalizada y bilateral y teniasis.

Fue tratado con Dexametasona 16 mg diarios y Fenobarbital 7 mg diarios.

\section{Exámenes de gabinete}

Electroencefalograma: desorganización y identificación de base difusa en ambos hemisferios cerebrales.

Ecoencefalograma: normal.

Radiografías simples de cráneo: normales.

Gamagrafía: no hay lesión ocupativa.

TAC: múltiples procesos granulomatosos tanto supra como infratentoriales, bilaterales con edema periférico.

Evolución. Como se ha dicho, el enfermo fue hospitalizado y se hizo lo siguiente:

Primero se trató la tenia y a continuación se administró al enfermo el praziquantel durante quince días a la dosis de $50 \mathrm{mg}$ por kilo de peso, administrando el medicamento en cápsulas.

Al octavo día aparecieron huellas de albúmina en la orina que desaparecieron en cuarenta y ocho horas; no hubo otro efecto tóxico de intolerancia o alérgico.

Desde la primera semana se notó franca mejoría en la sintomatología que desapareció por completo al finalizar la segunda semana.

A continuación se suspendió toda medicación y así permanece hasta el momento actual, asintomático y sin tratamiento medicamentoso (Figura 2).

\section{Criterios de curación}

1 Clínico. Totalmente asintomático y sin tratamiento desde hace tres meses.

- Exámenes de laboratorio de control. Orina, biometría hemática, tendencia hemorragípara, química sanguínea, bilirrubinas y transaminasas normales.

I LCR. Glucosa, 52; células, 5; linfocitos, 100\%; proteínas, 50 mg; Pandy, negativa; cultivos, negativos; bacterioscópico, negativo.

- Reacción de fijación del complemento. Negativa.

1 Electroencefalograma. Normal.

- Inmunológico. (Véase gráfica y cuadro.) Todo sugiere que el parásito está muerto. 


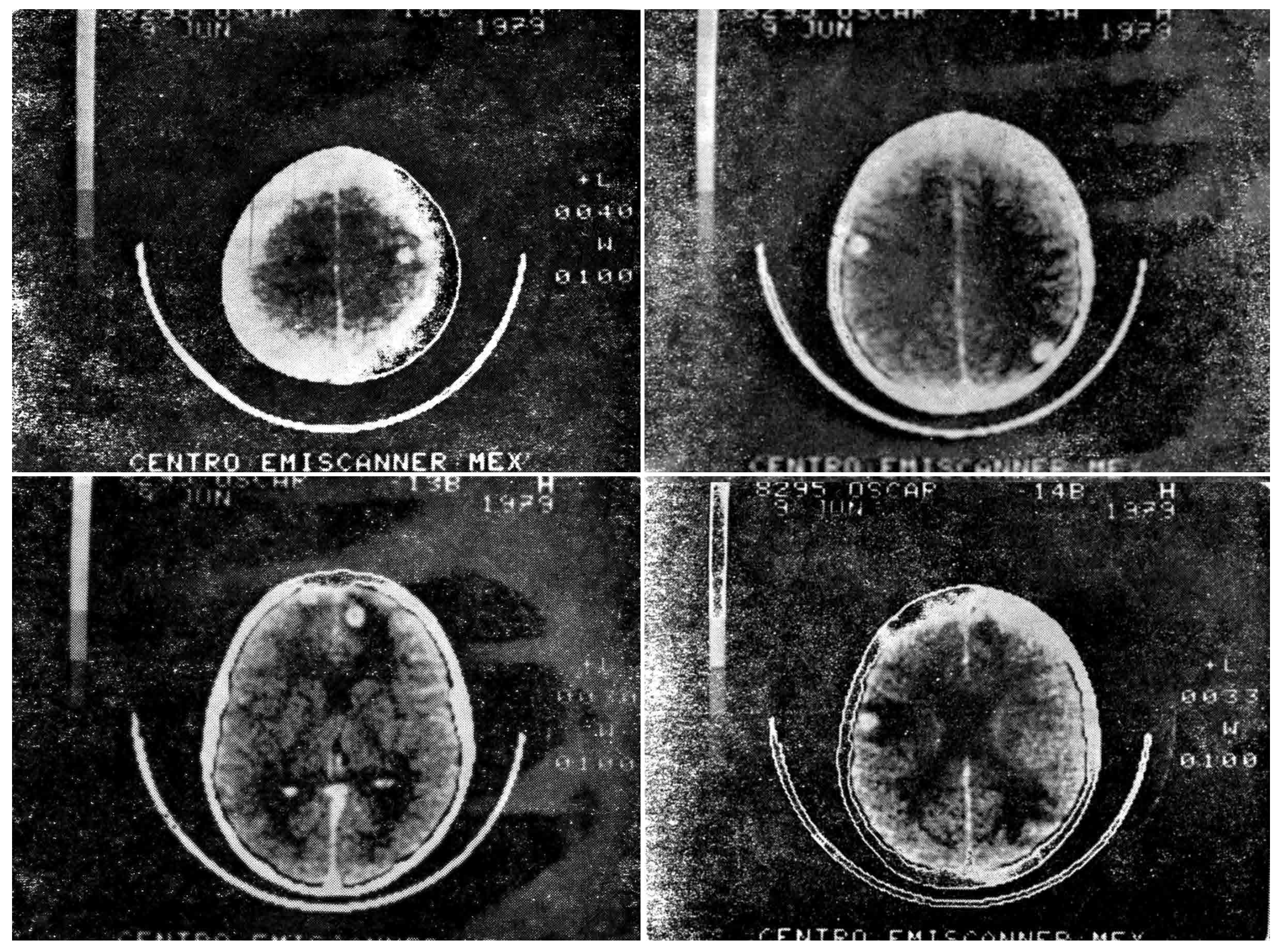




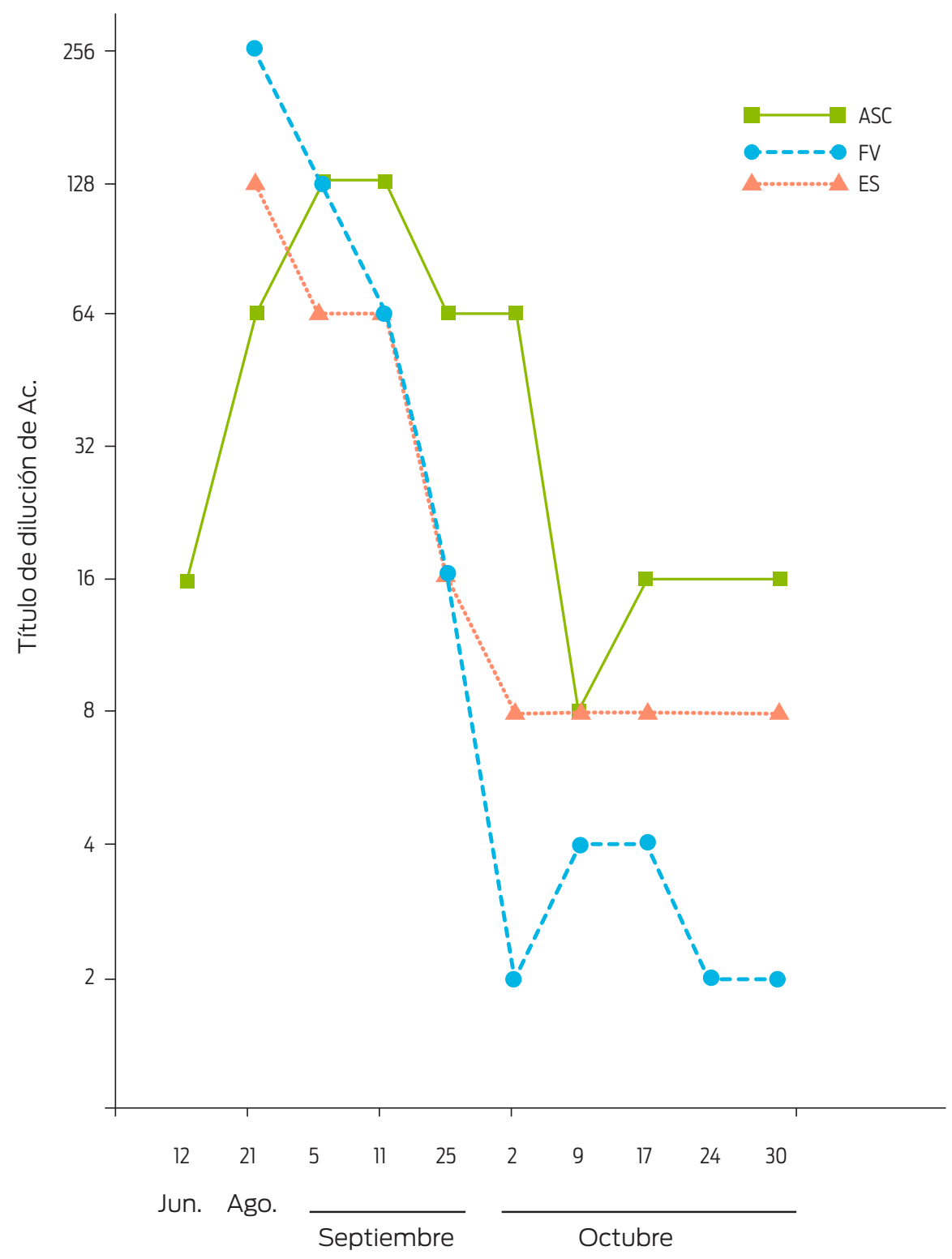

Evolución del título de anticuerpos del paciente O.D.L. por técnica de hemaglutinación indirecta con antígenos de C. cellullosae.

\begin{tabular}{|c|c|c|c|}
\hline \multirow{2}{*}{ Fecha } & \multicolumn{3}{|c|}{ Antigenos } \\
\cline { 2 - 4 } & ASC & FV & ES \\
\hline $12-$ VI-79 & $1: 16$ & $\ldots$ & $1: 256$ \\
\hline $21-V I-79$ & $1: 64$ & $1: 128$ & $1: 128$ \\
\hline $5-$ IX-79 & $1: 128$ & $1: 64$ & $1: 64$ \\
\hline $11-I X-79$ & $1: 128$ & $1: 64$ & $1: 16$ \\
\hline $25-I X-79$ & $1: 64$ & $1: 16$ & $1: 2$ \\
\hline $2-X-79$ & $1: 64$ & $1: 8$ & $1: 4$ \\
\hline 9-X-79 & $1: 8$ & $1: 8$ & $1: 4$ \\
\hline $17-X-79$ & $1: 16$ & $1: 8$ & $1: 2$ \\
\hline $24-X-79$ & $1: 16$ & $1: 8$ & $1: 2$ \\
\hline $30-X-79$ & $1: 16$ & $1: 8$ & \\
\hline
\end{tabular}


1 Radiológico. Desaparecen completamente las sombras anulares características de la presencia del cisticerco y el edema correspondiente.

- Anatomopatológico y biológico. No se han hecho por considerarlos innecesarios y peligrosos.

\section{Discusión}

I. El diagnóstico de cisticercosis intracerebral es absolutamente seguro por las siguientes razones:
a) Hay antecedente perfectamente claro de teniasis.
b) El cuadro clínico con hipertensión intracraneana violenta sin fenómenos de foco, con edema papilar; crisis convulsivas y deterioro mental progre- sivo, es típico.
c) Las imágenes radiológicas de los granulomas cisticercosos al CAT son también típicos.
d) El examen de LCR es compatible con cisticercosis.
e) La dosificación de anticuerpos es probatoria.
f) La reacción de fijación del complemento fue positiva.

II. Tampoco hay dudas de que el enfermo esté curado, por las siguientes razones:
a) Se encuentra asintomático a pesar de no recibir ningún tratamiento du- rante más de tres meses.
b) Las imágenes radiológicas típicas han desaparecido.
c) La dosificación de anticuerpos indica que los antígenos han desaparecido o están en vías de hacerlo (Figura 3).
d) La reacción a la cisticercosis en el LCR se ha vuelto negativa.
e) El electroencefalograma se ha normalizado.

III. Tampoco hay duda de que los cisticercos están muertos, por las siguientes razones:
a) Las imágenes radiológicas han desaparecido.
b) La actividad antigénica ha desaparecido.

IV. Si los cisticercos han muerto, esto se debió a la acción del medicamento por las siguientes razones:

a) Se advirtió clara relación entre la administración del medicamento y la mejoría progresiva de los síntomas a la semana.

b) Más tarde, al cabo de dos semanas, lo que observamos no sólo fue mejoría sino desaparición de los síntomas.

c) Esta mejoría-curación persiste a pesar de haberse suspendido toda medicación.

d) A medida que progresaba el tratamiento, se advertía con claridad la mejoría del cuadro clínico y la disminución de la tasa de anticuerpos circulantes, por lo cual no hay duda de que estos fenómenos, la mejoría y la 

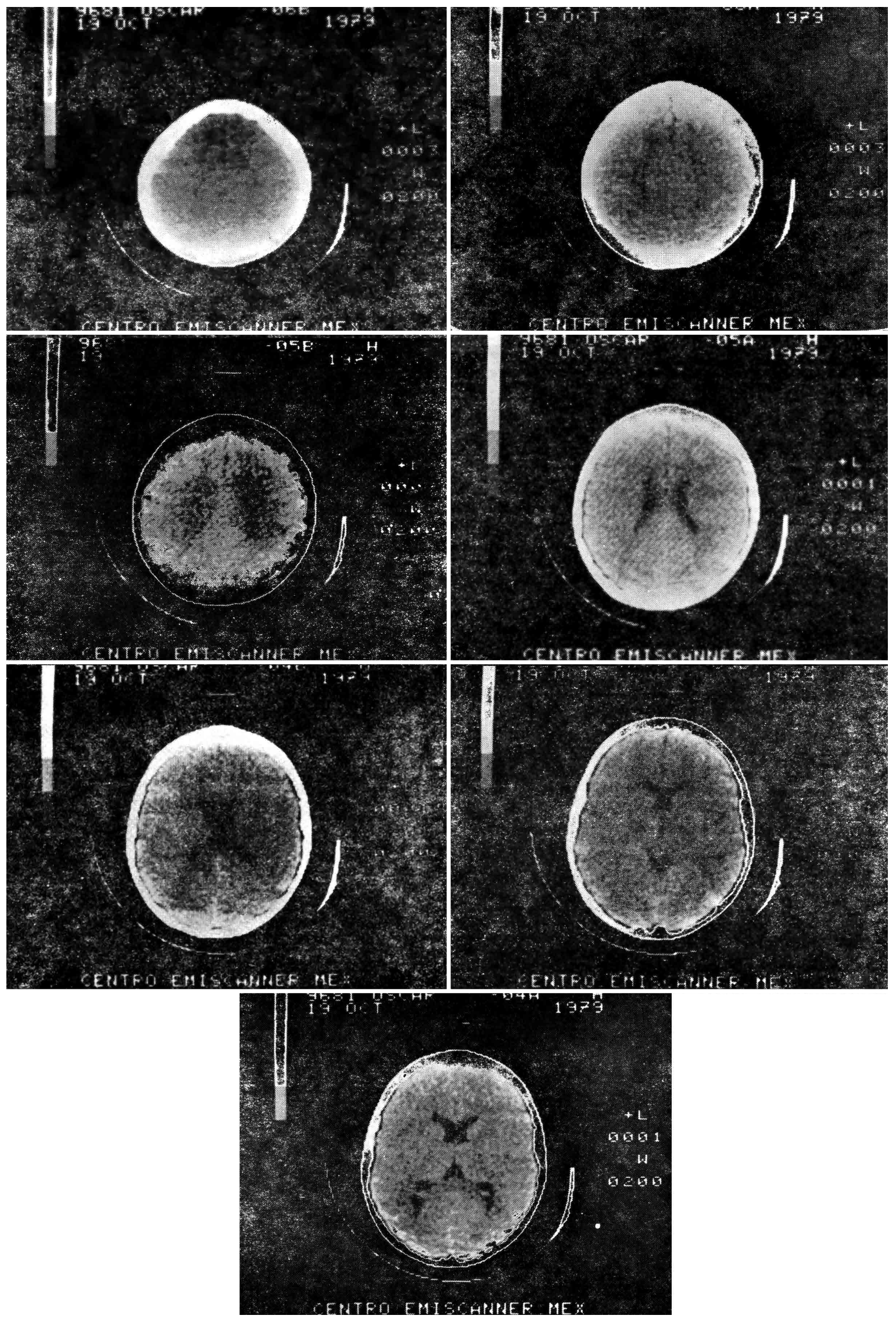

Figura 3. Después del tratamiento. 

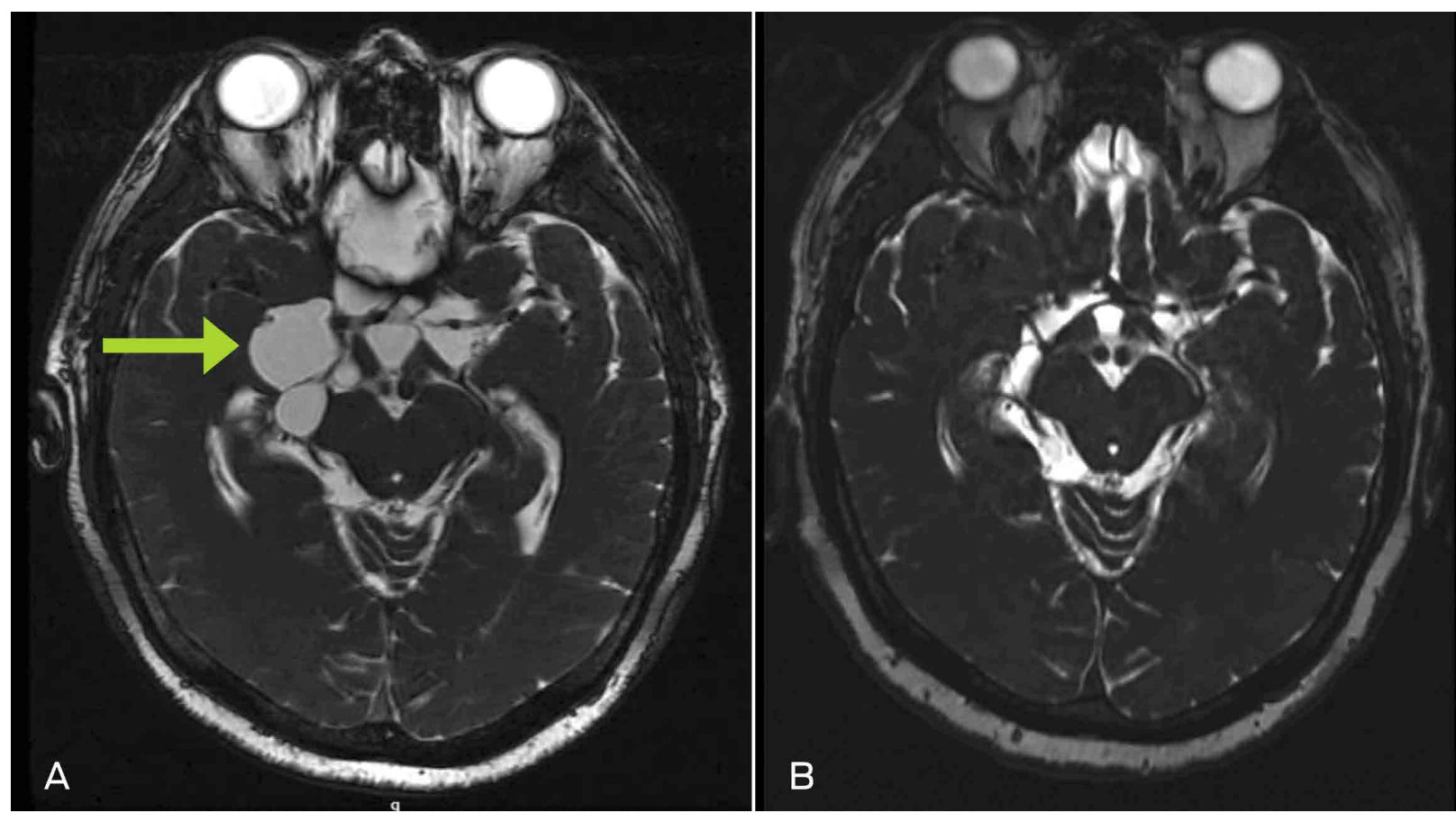

Figura 4. Imagen del encéfalo de un paciente antes (A) y después (B) del tratamiento contra neurocisticercosis extraparenquimatosa. Esta imagen, no incluida en el artículo original, muestra una resonancia magnética nuclear en la que se aprecia mejor la presencia de los cisticercos (A: flecha) y del encéfalo. Imágenes cortesía de los Dres. Roger Carrillo y Agnes Fleury.

disminución de la tasa de anticuerpos estaban en relación directa con la medicación que se estaba administrando.

e) Además todo esto se esperaba, no fue sorpresa, tomando en cuenta los antecedentes experimentales del estudio.

V. Si el enfermo ha curado después de la muerte de los cisticercos, es lógico afirmar que la curación se debe a la muerte del parásito y no a ninguna otra causa. Muerto el perro se acabó la rabia.

\section{Conclusiones}

El praziquantel es eficaz en el tratamiento de la cisticercosis cerebral, mata al cisticerco y cura la enfermedad y, en el caso presente, no originó reacciones alérgicas ni fenómenos tóxicos ni de intolerancia. El praziquantel es inferior a la profilaxis. 


\section{Agradecimientos}

Nos es particularmente grato agradecer la valiosa ayuda de las siguientes personas:

De nuestro antiguo amigo y compañero de toda la vida, doctor Andrés Bustamante Gurria, de quien constantemente estuvimos recibiendo estimulo moral y material que para nosotros resultó de valor inapreciable.

Del Secretario de Agricultura y Recursos Hidráulicos, Francisco Merino Rábago, pues comprendiendo la trascendencia de nuestro estudio se hizo cargo de todos los gastos de hospitalización del enfermo O.D.L.

Del Subsecretario de Salubridad, doctor Mario Calles López Negrete, quien ha puesto a nuestra disposición los cuantiosos recursos del Instituto de Salubridad y Enfermedades Tropicales.

Del Subsecretario de Asistencia, doctor Carlos Gual, por haber girado las órdenes correspondientes a los hospitales de su dependencia, especialmente al Hospital General.

Del Subsecretario de Ganadería, doctor Rubén Fernández Gómez, quien ha estado continuamente en contacto con uno de nosotros, el doctor Chavarría, y le ha brindado todas las facilidades necesarias para llevar al cabo sus estudios en las dependencias a su cargo.

Del doctor Manuel Gutiérrez Quiroz, del Laboratorio de Ecología de la Facultad de Medicina, Departamento de Inmunología, por haber hecho las dosificaciones de anticuerpos en el suero sanguíneo de nuestro enfermo.

Del doctor Rafael Méndez, Jefe del Departamento de Farmacología del Instituto de Cardiología, quien nos asesoró en todo lo relativo a satisfacer las exigencias de la Carta de Helsinky para experimentación en el hombre.

Del doctor Jorge Albores Saavedra, Jefe del Departamento de Anatomía Patológica del Hospital General de México, en la interpretación y registro gráfico de las preparaciones que le llevó el doctor Manuel Chavarría Ch.

A todos ellos deseamos manifestar nuestro más profundo reconocimiento.

\section{Referencias}

1. Ochoterena I. Contribución al conocimiento de la histopatología de la cisticercosis cerebral en México. Ann Inst Blol Méx. 1935;4:81-7.

2. Rojo de la Vega J, Ramirez Moreno S. Cisticercosis quística del cerebro curada por intervención quirúrgica. Rev Mex Psiq Neurol Med Leg 1939;5(29):17.

3. Ugalde A. Cisticercosis cerebral generalizada. Rev Hosp Gral. 1938;1(5).

4. Guevaraoropeza M. Tumor del ángulo ponto cerebeloso. Arch Neurol Y Psiq De Méx. 1938;(6):369.

5. Robles C. Consideraciones respecto a la cisticercosis del IV ventrículo. Gaceta Médica de México. 1941;71(6):746-55.

6. Costero I. Anatomía patológica de la cisticercosis cerebral. Memoria de la VI Asamblea Nacional de Cirujanos. Méx. 1944.

7. Mazzoti L. Datos sobre la cisticercosis en México. Rev del Inst Salubridad y Enf Trop 1944;5:283.

8. Robles C. Consideraciones acerca de la cisticercosis cerebral. Arch de Neuroc 1940;3(1):23-43. 
9. Briseño CE, Biagi F, Martínez B. Cisticercosis. Observaciones sobre 97 casos de autopsia. Prensa Med Mex. 1961;26:193.

10. Costero I. Tratado de anatomía patológica. Tomo II, México: Atlante; 1946. p. 1485-95.

11. Robles C. Consideraciones acerca de 100 casos de tumor cerebral operados. Gaceta Médica de México. 1940;70:(3).

12. Robles C, Reyes Armijo E. Uso de la sonda de Puddenz en el tratamiento de la cisticercosis cerebral. Gaceta Médica de México. 1966;96(8):799-810.

13. Salazar Mallen M. Revista de Investigación de Salud Pública. 1972;32:1-7.

14. Andrews P. Pharmacokinetic studies with Droncit in animals using a Biological Assay. Vet Med Rev. 1976;2:154-65.

15. Steiner K, Garbe A. The fate of Praziquantel in the organism II distribution in rats. Europ. Jour. Drug Metabolism and Pharmacokinetics. 1976;(2):97-106.

16. Murmann P, et al. Notes on the tolerance of Droncit. Vet Med Rev. 1976;2:142-53.

17. Leopold G, Ungethum W, Groll E, Dickmann HW, Nowak H, Wegner DHG. Clinical pharmacology in normal volunteers of praziquantel. Europ J Clin Pharmacol. 1978;14:281-91.

18. Chavarría M, Díaz González D. Droncit en el tratamiento de la cisticercosis porcina. Esp Vet. 1979;1-5-6:160-5.

19. Molina Pasquel C. Comunicación personal. 